\title{
ON DESIGN OF EXPRESSWAY EMBANKMENT IN SEISMICALLY ACTIVE AREA WITH EMPHASIS ON LIFE CYCLE COST
}

\author{
IKuo Towhata ${ }^{\text {i) }}$, IKumasa YoshidA ${ }^{\text {ii) }}$, Yukihiro Ishihara ${ }^{\text {iii)}}$,

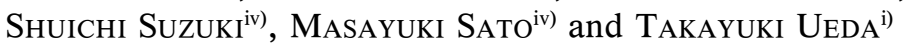

\begin{abstract}
This paper addresses the role played by life cycle cost (LCC) calculation in a seismic design of geotechnical structures. The recent trend towards the performance-based design is pushed further to arrive at the optimum design by using the LCC principle. Since geotechnical engineering still has many uncertainties in the LCC calculation, consideration and decision were made to solve each of them. As a research product, an example calculation was made of an expressway embankment whose interruption upon a major earthquake would cause significant damage to the economy. The results show that the indirect loss due to the elongated travel time during the interruption is the most significant source of LCC. Accordingly, it was found that the choice of design specification is affected by, whether a conventional seismic design principle is employed or LCC-based principle is made use of.
\end{abstract}

Key words: earthfill, deformation, design, earthquake damage, life cycle cost, seismic performance (IGC: E8/H0)

\section{INTRODUCTION}

The structural design code in Japan has changed from a conventional allowable stress design to a limit state design. Moreover, the shift to a performance-based design system, which clearly specifies the performance of a structure, is also at present being considered. The ISO code for earthquake geotechnical engineering (ISO23469, 2004) puts a special emphasis on performance based design. The performance of a structure is also important from an economic or financial viewpoint. In recent years, there has been an increasing demand from expressway companies, governments and organizations that manage infrastructures, for cost optimization strategies of design and maintenance of structures during their service life. Usually, construction costs, inspection costs, maintenance costs, user costs, and expected failure costs are included as essential factors for a life-cycle cost (LCC) analysis. During their design working life, structures are exposed to hazards that could lead into unfavorable states and which in turn would lead to negative consequences, in other words, expected failure costs or risk. ISO/IEC Guide 73 (2002) gives a definition that risk is a combination of the consequence of an event and its probability. In this paper, risk is defined as the expected failure cost, which is the product of the consequence in monetary terms and its probability.

The risk corresponding to such events must be main- tained under an acceptable level. Any design code prescribes a series of design criteria in the design of structures. These criteria are often based on the target reliability levels which must be predetermined by judging the risk due to the exceedance of the limit states of interest. The concept of LCC minimum provides a basis for codes writers as well as designers to reasonably set the target reliability level. The objective of a LCC-based design is to allocate limited resources optimally for stakeholders such as the general public, local community, individuals, and various organizations. The definition of stakeholder is also given in ISO document (ISO/IEC Guide 73, 2002), which is any individual, group, organization or authority that can affect, be affected by, or perceive itself to be affected by, a risk. Detailed explanations as to the management or assessment of risk are given in several guidelines or books, such as Australian/New Zealand Standards (2004), and Stewart and Melcher (1997).

Structures may be exposed to various possible hazards occurring during their service lives. Representative natural hazards are typhoon and earthquake in Japan. The frequency of a failure event caused by a large earthquake is rare, yet its consequences are substantial. Seismic risk assessment of buildings or infra-structures has been studied by Takahashi et al. (2004), Yoshida (2005), and Furuta and Frangopol (2005) among others. However, the considered consequence of a seismic failure event has been limited to restoration cost and economic loss to the owner

i) Professor, University of Tokyo, Japan (towhata@geot.t.u-tokyo.ac.jp).

ii) Professor, Tokyo City University, Japan.

iii) Giken Engineering, Japan (formerly Graduate Student, University of Tokyo, Japan).

iv) Tokyo Electric Power Services, Japan.

The manuscript for this paper was received for review on February 5, 2008; approved on November 6, 2008.

Written discussions on this paper should be submitted before July 1, 2010 to the Japanese Geotechnical Society, 4-38-2, Sengoku, Bunkyo-ku, Tokyo 112-0011, Japan. Upon request the closing date may be extended one month. 
or has simply been assumed. Moreover, there are problems in LCC approach which are specific to geotechnical engineering, which will be discussed later on.

In this paper, an example of LCC-based geotechnical design with seismic risks taken into consideration is demonstrated using a hypothetical expressway embankment model. The benefit loss to the public is considered to be the interruption of an expressway. This consequence is modeled by developing a function in terms of subsidence caused by earthquakes. Thus, the risk is estimated on the basis of a continuous limit state, namely the magnitude of subsidence.

\section{CONVENTIONAL DESIGN OF SEISMIC SLOPE STABILITY}

\section{Model of Embankment}

In this paper an embankment of a hypothetical expressway in an area where seismic activity is high is studied. Furthermore, the embankment rests on a soft ground, which requires soil improvement to provide sufficient earthquake resistance. When this type of embankment is connected with a bridge that is supported on a pile foundation and is free of subsidence, the differential settlement between them could be fatal to road transportation (Fig. 1). Figure 2 shows the cross sectional view of the embankment model. Design parameters for the improvement consist of the width of the area and the improvement ratio of either sand compaction pile (SCP) or deep mixing method (DJM). Soil properties of the embankment and subsoil are also shown in Fig. 2. They stand for soil properties prior to soil improvement. The shear strength of soft subsoil is improved by different extents depending on the improvement ratio. When SCP is practiced, soil properties of sand piles are given by unit weight $=19.0 \mathrm{kN} / \mathrm{m}^{3}$ and internal friction angle $=37$ degrees. When DJM is employed, on the other hand, the undrained strength, $C_{\mathrm{u}}$, of the grouted soil is assessed by the improvement ratio multiplied by $300 \mathrm{kN} / \mathrm{m}^{2}$. Fifty design plans were examined for the best choice of soil im- provement work, which are illustrated in Fig. 3. In this figure, five improvement widths of $0,5,10,15$, and $20 \mathrm{~m}$, and two methods of soil improvement, SCP and DJM, were compared. The improvement ratio was also variable, being such as 20, 25, 30, and $35 \%$ for SCP, and 20 , $30,40,50,60$, and $70 \%$ for DJM. This brings the total to fifty design plans.

Costs for the soil improvement work were calculated by using the improvement ratio, volume of improved

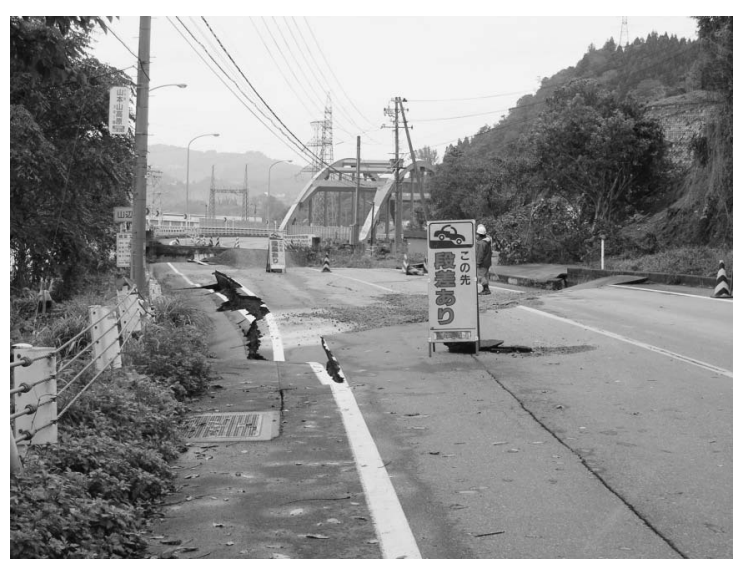

Fig. 1. Differential settlement between road embankment and bridge

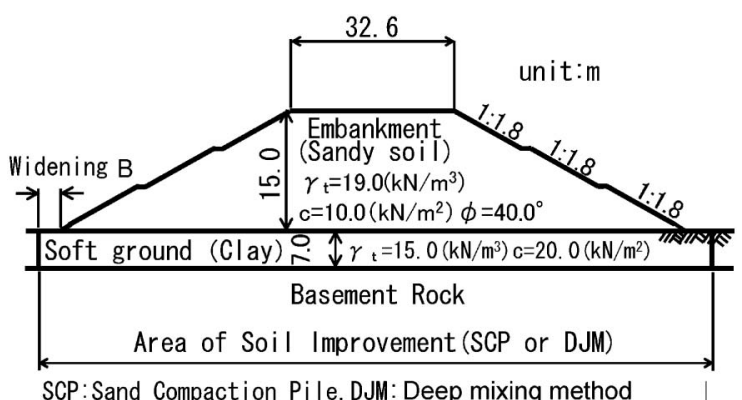

Fig. 2. Cross section of embankment model
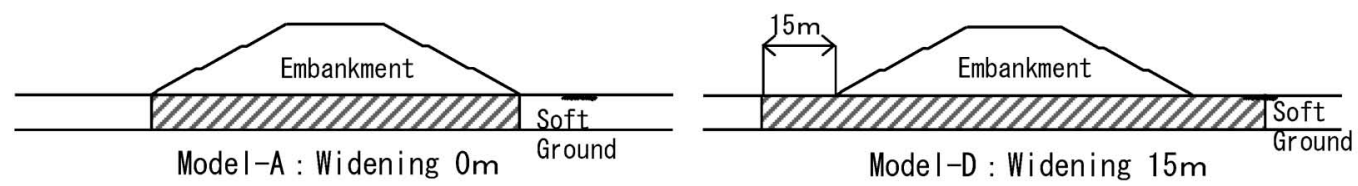

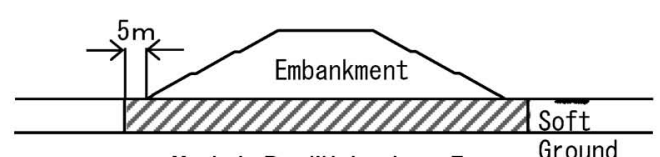

ModeI-B : Widening $5 \mathrm{~m}$

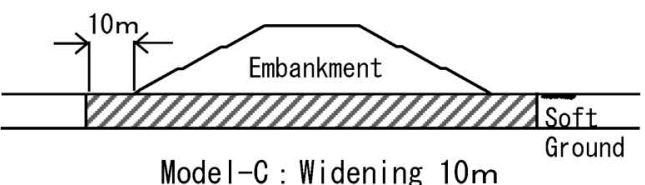

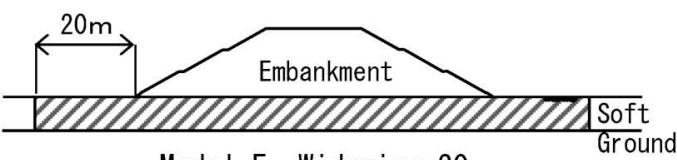

Model-E : Widening $20 \mathrm{~m}$

《Improvement rate》

- SCP $\Rightarrow 4$ cases $(20, \quad 25, \quad 30,35 \%)$

- DJM $\Rightarrow 6$ cases $(20,30,40,50,60,70 \%)$

Fig. 3. Fifty design plans for soil improvement with respect to improvement width, methods, and improvement ratio 
soil, and the unit price as indicated in Table 1. The length of the improvement is assumed to be $100 \mathrm{~m}$. For example, the cost for the design plan of SCP with improvement ratio of $30 \%$ is estimated in Japanese currency of Yen as 3,700 times the improved soil volume $\left(\mathrm{m}^{3}\right)$. The cost for DJM with improvement ratio of $50 \%$, for example, is estimated by $0.5 \times 8,000 \times$ the soil volume $\left(\mathrm{m}^{3}\right)$. This soil improvement cost is called the initial cost hereafter.

\section{Estimation of Safety Factors and Construction Costs}

In order to compare the conventional design with a LCC-based design, the result obtained by conventional design procedure is briefly summarized in this section. A limit state is defined in terms of the safety factor, which is defined as the ratio of the resisting force to the driving force along the sliding surface in conventional design practice. These forces are calculated following the design procedure (Japan Road Association, 1999). Static lateral force defined by a seismic coefficient is applied to the embankment, and then the safety factor is calculated by using the limit equilibrium of a rigid body, which is known as Fellenius Method. Seismic coefficient of $K_{\mathrm{h}}=0.16$ is specified by a road design code (Japan Road Association, 1999) at a site that is situated on a base ground type I (firm soil) in the Tokyo Metropolitan Area. The most

Table 1. Unit cost for soil improvement and restoration

Unit: Yen $/ \mathrm{m}^{3}$

\begin{tabular}{l|cc}
\multicolumn{1}{c|}{ Item } & \multicolumn{2}{c}{ Unit cost } \\
\hline Subgrade & \multicolumn{2}{|c}{2,250} \\
Pavement & \multicolumn{2}{|c}{2,280} \\
Embankment & \multicolumn{2}{|c}{2,150} \\
\hline Sand compaction pile (SCP) & Improvement ratio \\
& $20 \%$ & 2,400 \\
& $25 \%$ & 3,100 \\
& $30 \%$ & 3,700 \\
& $35 \%$ & 4,300 \\
\hline Deep mixing method (DJM) & \multicolumn{2}{|c}{8,000} \\
\hline
\end{tabular}

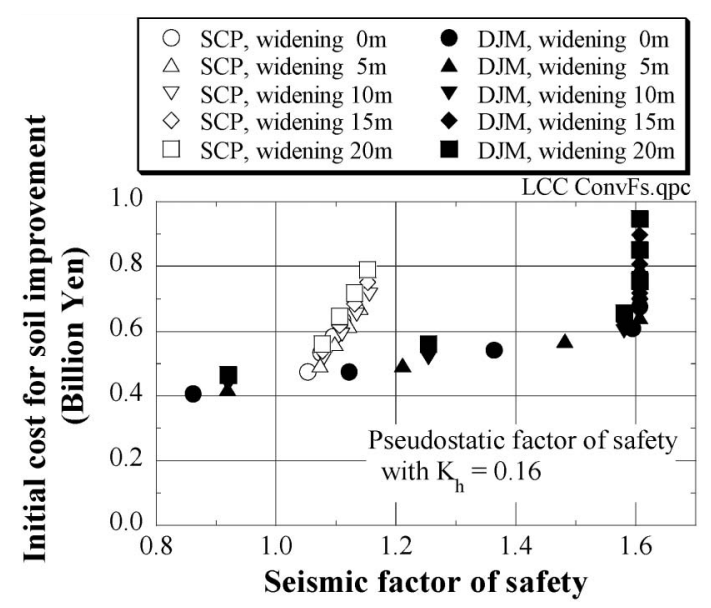

Fig. 4. Seismic safety factor estimated by conventional design procedure and its initial cost (improvement cost) critical sliding mechanism is detected by a random search, in which slip surfaces are randomly generated and the one with the lowest safety factor is found.

Figure 4 shows the seismic safety factor thus estimated that varies with the initial cost. The safety factor should be greater than 1.0. The design plan of which cost is minimum and safety factor is larger than 1.0, is the case of SCP with no widening and an improvement ratio of $20 \%$.

\section{BASIC PRINCIPLES IN LCC-BASED DESIGN OF SOIL IMPROVEMENT}

\section{General Remarks}

The life cycle cost is conventionally defined as the total monetary cost that consists of the initial construction cost $\left(C_{\mathrm{i}}\right)$, the maintenance cost $\left(C_{\mathrm{m}}\right)$, and the seismic risk cost $\left(C_{\mathrm{e}}\right)$ :

$$
\mathrm{LCC}=C_{\mathrm{i}}+C_{\mathrm{m}}+C_{\mathrm{e}}
$$

The maintenance and seismic costs are assessed over the entire life (service period) of a concerned structure. It is supposed that a design option that minimizes LCC is the most optimal design. As Fig. 5 illustrates, the greater initial construction cost would improve the quality of a structure, and hence reduce both maintenance and seismic risk costs.

Although this idea is easy to understand for most types of structures, the life period of a geotechnical structure cannot be determined clearly. There are dikes and road embankments that have been in service for hundreds of years or longer, for which the life is not clearly defined. To cope with this problem, the authors visited governments and authorities which are in charge of the maintenance of dikes and embankments. It was first found that most part of the maintenance cost is spent on cutting grasses, inspection of drainage pipe, and similar business that have nothing to do with the construction quality. Moreover, although it was initially expected that good quality of construction would reduce later subsidence of embankments and its restoration cost, it was found that the road pavement was repaired not only due to subsidence but also due to weathering and abrasion. Similarly, the height of a river dike was raised not because of the subsidence but for improving the quality of regional flood disaster mitigation. Consequently, it was decided in

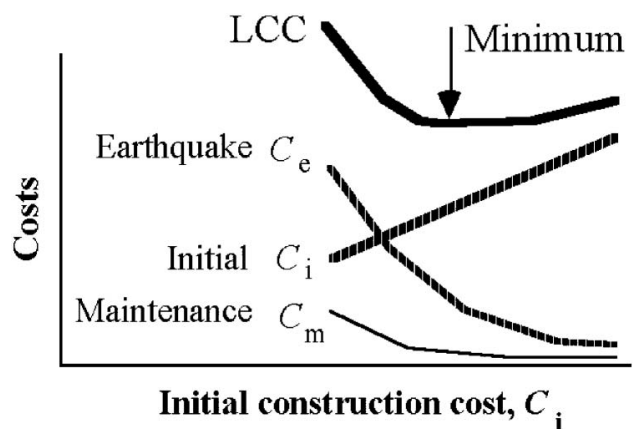

Fig. 5. Conceptual illustration of life cycle cost 
the present study to eliminate the maintenance cost from the current study. This does not affect the conclusion of this study, because the maintenance cost is smaller than the seismic risk cost, as will be presented later, and also because the maintenance cost is independent of the construction cost, without affecting the choice of the soil improvement option. This is considered to be a characteristic of geotechnical structures except for very extreme situations. It seems, in contrast, that maintenance efforts of concrete and steel structures depend on the quality of initial construction, and therefore, their LCC calculation requires maintenance cost to be considered. The life of a geotechnical structure is assumed to be 80 years, furthermore. After this time period, the life style of people and public demand would change completely and the value of the original structure would be lost. Finally, the initial cost in this paper designates that for soil improvement only. This is because the construction cost for an expressway embankment is independent of the choice of soil improvement. The seismic risk is a product of monetary consequence and its probability, namely expected failure cost. The design plan is determined from the viewpoint of minimum LCC among the above fifty design cases in a LCC-based design.

\section{Consequence of Earthquake Effect}

Details of seismic cost $\left(C_{\mathrm{e}}\right.$ in Eq. (1)) or scenario consequence due to failure of an embankment are described hereafter. For clarity, the present paper employs an embankment of expressway resting on cohesive subsoil that is adjacent to a bridge and is subject to differential subsidence upon a strong earthquake. The consequence includes damage of structures, loss of functionality, human injury and death, and economic loss caused by the failure of a particular structure that concerns stakeholders. It is assumed that a strong earthquake causes subsidence or dip in an expressway embankment (Fig. 6), which in turn leads to traffic accidents and interruption for a certain period. Injury, loss of human life, and restoration cost of the structure are classified as direct loss, whereas economic loss caused by the expressway interruption is called indirect loss.

The expressway embankment discussed in this paper is hypothetical. However, in order to have a realistic numerical example, real traffic volume and other data were utilized. These data were taken from the Tomei expressway between Atsugi and Yokohama-Machida Interchanges. Note that the Tomei expressway is a part of the nation's No. 1 expressway connecting Tokyo and Osaka. Hence, it is a good example to investigate the economic indirect loss upon a strong earthquake. Figure 7 shows the expressway and local routes for detour. There are three embankments in the studied section. Hence, the following cost calculation concerns three critical embankments. The traffic volume of the expressway and assumed detour routes are summarized in Table 2. Table 3 shows the traffic volume of detour routes when the expressway is interrupted. The traffic volumes after the interruption are estimated by traffic flow analyses, assuming that all the

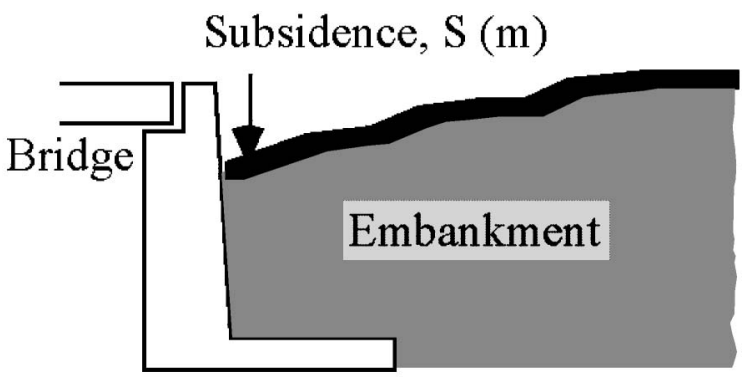

Fig. 6. Subsidence of embankment adjacent to bridge abutment

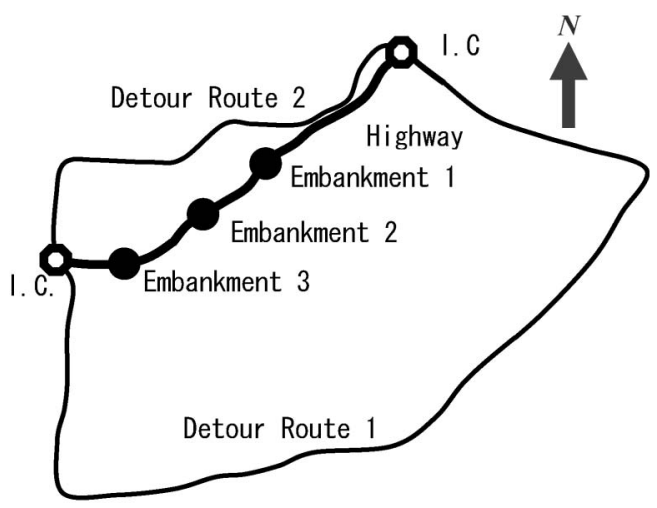

Fig. 7. Investigated routes of expressway and detours

Table 2. Traffic volume without interruption of expressway

\begin{tabular}{l|rrrrr}
\hline & \multicolumn{5}{|c}{ Traffic volume (cars/day) } \\
\cline { 2 - 6 } & Automobile & \multicolumn{1}{c}{ Bus } & Van & Truck & Total \\
\hline Expressway & 59,600 & 1,289 & 11,091 & 48,699 & 120,679 \\
Detour route 1 & 38,191 & 401 & 8,820 & 17,077 & 64,489 \\
Detour route 2 & 27,233 & 206 & 7,489 & 7,594 & 42,522 \\
\hline
\end{tabular}

Table 3. Traffic volume after the interruption of expressway

\begin{tabular}{l|ccccc}
\hline & \multicolumn{5}{|c}{ Traffic volume (cars/day) } \\
\cline { 2 - 6 } & Automobile & Bus & Van & Truck & Total \\
\hline Expressway & 0 & 0 & 0 & 0 & 0 \\
Detour route 1 & 92,069 & 1,566 & 18,846 & 61,101 & 173,582 \\
Detour route 2 & 32,955 & 330 & 8,554 & 12,269 & 54,108 \\
\hline
\end{tabular}

interrupted traffic of the expressway take either route 1 or 2.

The present study employs the subsidence of the top of the expressway embankment as an index for the extent of seismic effects. In particular, the subsidence, $S$, at an interface between cut and fill or between fill and a bridge abutment (Fig. 6) may cause car accidents if it is significant. In accordance with the practice by Railway Technical Research Institute (2003), the subsidence was calculated by using the Newmark rigid block analogy (Newmark, 1965) on the cross section in Fig. 2 in which a gigantic earthquake of magnitude $=8$ in the tectonic subduction zone and an inland one of magnitude $=7$ at a 


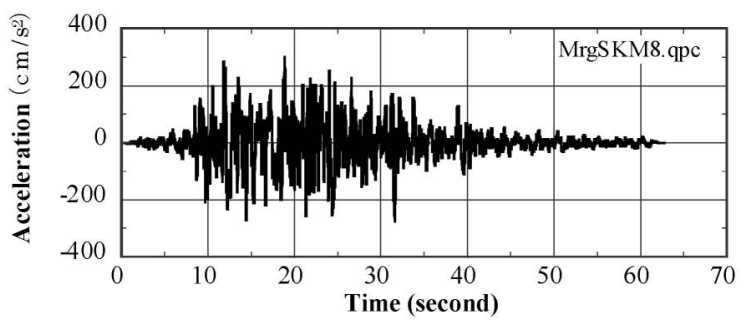

(1) Inter-plate earthquake of magnitude 8

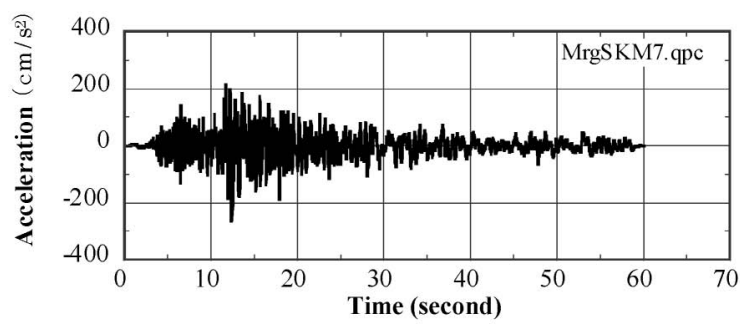

(2) Earthquake of magnitude $=7$ caused by inland crustal, intra-plate,

and smaller inter-plate mechanisms

Fig. 8. Input seismic motions for dynamic analyses

Table 4. Considered Losses in LCC estimation

\begin{tabular}{l|l|l}
\hline \multirow{2}{*}{ Direct } & $\mathrm{D}_{1}:$ Human Loss & $\begin{array}{l}\text { Traffic accident due to failed } \\
\text { embankments }\end{array}$ \\
\cline { 2 - 3 } & $\mathrm{D}_{2}:$ Restoration Cost & Restoration of failed embankments \\
\hline \multirow{4}{*}{ Indirect } & $\mathrm{D}_{3}:$ Detour Loss & $\begin{array}{l}\text { Economic loss due to extension of } \\
\text { time and distance }\end{array}$ \\
\cline { 2 - 3 } & $\mathrm{D}_{4}:$ Environmental Loss & Emission of CO2, NOx, Noise \\
\cline { 2 - 3 } & $\mathrm{D}_{5}:$ Traffic Accident Loss & $\begin{array}{l}\text { Traffic accident due to the traffic } \\
\text { congestion in detour route }\end{array}$ \\
\cline { 2 - 3 } & $\mathrm{D}_{6}:$ Toll Loss & Missing toll of expressway \\
\hline
\end{tabular}

shorter epicentral distance were employed (Fig. 8). Since the intensity and occurrence of these earthquakes are of probabilistic nature, the calculated subsidence was probabilistic as well.

Both direct and indirect losses are modeled as a function of subsidence. The estimated consequences are restoration, human, detour, traffic accident and environmental losses which are summarized in Table 4 . The first two are direct losses while the rest are indirect losses. Details of these losses are described in the following chapters.

\section{CALCULATION OF DIRECT LOSSES}

Human loss/injury and restoration costs are evaluated as follows. First, in cost-benefit analyses, monetary value must be determined for human life and injury, often causing great controversy. This human loss is caused by car crash at a significant subsidence. Human life is conventionally assumed to be $31.5 \mathrm{MY}$ (million Yen) per person in cost-benefit analyses for road investment in Japan. However, this value is much lower than real loss in the bereaved family. It is also very small as compared with

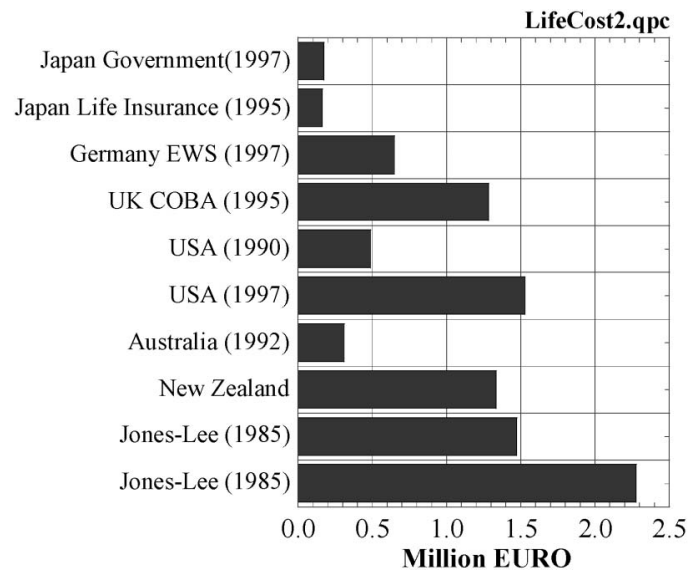

Fig. 9. Costs of human life in different nations (after Jones-Lee et al., 1985)

those in other nations (see Fig. 9).

One of the reasons for the difference is the method of calculation. In the previous Japanese method, the life cost calculation is based on the lost income during the rest of life. This generally leads to lower costs. Conversely, the GNP-based method calculates the life cost of a person by dividing the total product by population. For example, ICAF (Rackwitz, 2002, 2004) calculated with statistics in 2004 to give $247 \mathrm{MY}$ in US, $226 \mathrm{MY}$ in UK, and 238 MY in Japan. Considering these figures, the present study employs $200 \mathrm{MY} /$ person.

The human loss is calculated by Eq. (2) in this study.

$$
\begin{aligned}
& D_{1}=0.5 Y P, \\
& Y=189.8 S^{2}+10.7 S-0.5 \quad \text { (million Yen) }
\end{aligned}
$$

where $Y$ stands for the mean human loss per person, being inclusive of life loss as well as heavy and light injuries. This equation was derived by assuming that the human loss is equivalent to human life loss when subsidence $S$ is $1.0 \mathrm{~m}, 70 \%$ of human life loss when $S$ is $0.5 \mathrm{~m}$, and $0 \%$ when $S$ is $0.03 \mathrm{~m}$.

$P$ is the number of passengers in all the vehicles involved in a possible car crash at the seismic subsidence. Since the present study assumes that vehicles that cannot stop before the subsidence is involved in the accident, $P$ is a function of the number of vehicles in the expressway $(Q /$ hour in Table 2$)$, vehicle velocity, $V(\mathrm{~km} / \mathrm{s})$, and the mean number of passengers per car $(p)$ :

$$
P=\frac{Q}{1000 \times V} \times p \times B(V)
$$

It is hypothesized that the average car velocity is $V=80$ $\mathrm{km} / \mathrm{h}$ and cars need $B=80 \mathrm{~m}$ to stop completely. Those cars within $80 \mathrm{~m}$ from the subsidence are involved in a crash to different extents, depending on the final velocity. The number of passengers per car $(p)$ is set equal to 1.5 , considering 1.44 on weekdays and 2.01 on weekends/ holidays (Public Works Research Institute, 2004). The coefficient 0.5 in Eq. (2) accounts for the difference of crash severity because some vehicles near a subsidence cannot reduce the speed, while others at a greater distance 


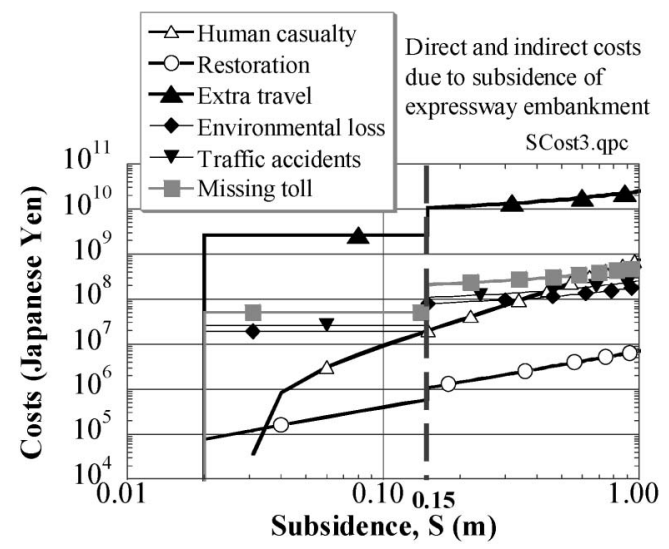

Fig. 10. Failure costs model costs based on subsidence of expressway embankment

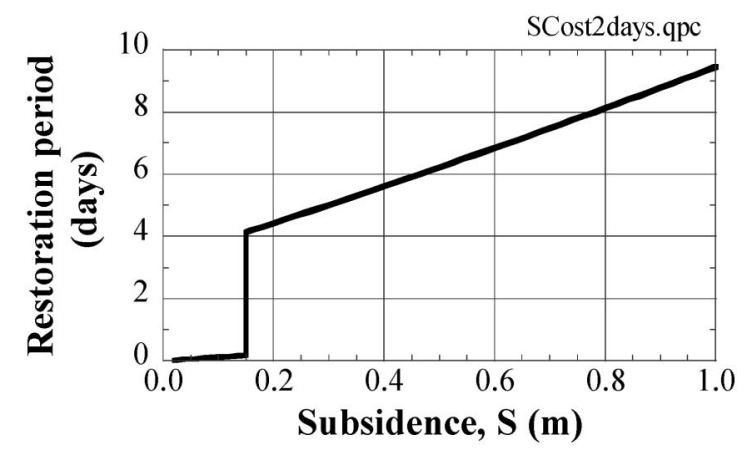

Fig. 11. Expected restoration time changing with subsidence

can reasonably slow down before crash. See Fig. 10 for variation of human cost with $S$.

Restoration cost is calculated using the following simple equation.

$$
D_{2}=1.3 \sum_{\mathrm{i}} 25 S W H_{\mathrm{i}} C_{\mathrm{i}}
$$

where $S$ is the subsidence caused by an earthquake (m), $W$ the width of the expressway $(\mathrm{m}), H_{\mathrm{i}}$ the depth of a material $i$ for restoration construction, $C_{\mathrm{i}}$ the unit price of the material $i$, and 1.3 a coefficient for consideration of overhead cost. The length of the restored road is assumed to be $25 \mathrm{~S}(\mathrm{~m})$ so that the surface slope after restoration would be reduced to $4 \%$. Furthermore, when the subsidence is less than $0.15 \mathrm{~m}$, the overlay method is adopted. In contrast when the subsidence exceeds $0.15 \mathrm{~m}$, the damaged pavement is removed, the embankment is reconstructed, and the road is newly paved. Discontinuity at $S=0.15 \mathrm{~m}$ is seen in Fig. 11 due to the differences of the restoration method. The threshold to minimum damage state is assumed to be $2 \mathrm{~cm}$ because of the $5 \mathrm{~cm}$ thickness of the surface asphalt pavement. The obtained restoration loss is illustrated in Fig. 10. Finally, on the basis of experiences of similar restoration works, the restoration time, which is the traffic interruption time, was assessed as illustrated in Fig. 11.

\section{CALCULATION OF INDIRECT LOSS}

It is assumed that there are three embankments as shown in Fig. 7 and their seismic fragilities are the same for simplicity. If any of the embankments fails, expressway traffic is interrupted. The interruption period, $T$, in days was assessed as shown in Fig. 11.

The traffic from the interrupted expressway causes traffic congestions in detour routes (Fig. 7) and the travel time is elongated. This time elongation is one of the indirect losses and is designated by $D_{3}$. It obstructs the economic activities, and increases fuel consumption. This loss is evaluated by

$$
\begin{aligned}
& D_{3}=\sum_{\mathrm{i}} \sum_{\mathrm{j}}\left(Q_{\mathrm{ij}} C_{\mathrm{ij}}-Q_{\mathrm{ij}}^{\prime} C_{\mathrm{ij}}^{\prime}\right), \\
& C_{\mathrm{ij}}=t_{\mathrm{i}} a_{\mathrm{j}}+l_{\mathrm{i}} b_{\mathrm{j}}, \quad C_{\mathrm{ij}}^{\prime}=t_{\mathrm{i}}^{\prime} a_{\mathrm{j}}+l_{\mathrm{i}} b_{\mathrm{j}}
\end{aligned}
$$

where, $D_{3}$ stands for the detour loss per day (Yen/day), $Q_{\mathrm{ij}}^{\prime}$ and $Q_{\mathrm{ij}}$ the number of vehicles per day of vehicle type $j$ on the route $i$ before and after interruption of the expressway, $C_{\mathrm{ij}}^{\prime}$ and $C_{\mathrm{ij}}$ the general expense before and after interruption, $t$ and $t^{\prime}$ the travel time (minutes) before and after interruption, $a_{\mathrm{j}}$ the time value of vehicle type $j, l_{\mathrm{i}}$ the link length $(\mathrm{km})$ of route $i$, and $b_{\mathrm{j}}$ the driving expense of vehicle type $j$. Details of economic loss estimation procedure is described in many cost-benefit manuals. Note that $D_{3}$ and the following indirect losses are multiplied by the interruption period, $T$, in Fig. 11 to determine the entire indirect loss.

The environmental loss, $D_{4}$, is the monetary loss due to the increase of $\mathrm{CO}_{2}$ and $\mathrm{NO}_{\mathrm{x}}$ emission and the traffic noise level. It is noteworthy that these problems decrease along the interrupted expressway, while they increase along detour routes where the traffic increases. The estimated environmental loss based on a guideline by Research Committee on Assessment of Investment on Road (1998) is demonstrated in Fig. 10.

The traffic congestion in detour roads increases the number of traffic accidents, while it disappears in the interrupted expressway. The traffic accident loss, $D_{5}$, in the monetary loss was assessed by the aforementioned guideline as seen in Fig. 10.

Finally, the missing toll of the expressway, $D_{6}$, was calculated by using the number of daily traffics under normal conditions and the toll money particularly concerning the interrupted section of the expressway.

$$
D_{6}=\frac{Q_{\mathrm{p}} \times l_{\mathrm{p}}}{\sum_{\mathrm{k}} Q_{\mathrm{k}} \times l_{\mathrm{k}}} \times f \quad(\text { Yen } / \text { day })
$$

in which $Q_{\mathrm{k}}$ and $l_{\mathrm{k}}$ stand for the daily traffics and length of expressway section ' $k$ ', while $Q_{\mathrm{p}}$ and $l_{\mathrm{p}}$ designate those in the interrupted section. Moreover, $f$ is the daily toll income of the entire expressway. Consequently, the result is shown in Fig. 10. In spite of the calculation shown above, the relevancy in including the missing toll is controversial. It is also considered that the missing toll is a loss to the highway authority alone, creating no loss to the regional and national economies. When the indirect 
loss to the national economy is interested in as is the present case, this loss may have to be eliminated from the LCC calculation. Although this opinion deserves attention, the present study includes the missing toll. This would not affect the final conclusion because the toll loss is much smaller than the aforementioned detour loss.

In conclusion, it is evident in Fig. 10 that the indirect loss concerning the elongated travel time is the most significant component. The entire earthquake cost is obtained by adding all the components in Fig. 10 and is denoted by $D_{\mathrm{e}}(S)$ in what follows.

\section{PROBABILISTIC CALCULATION OF SEISMIC COST}

As was mentioned above, the present study is based on a probabilistic consideration of the design input earthquake, and consequently, the subsidence, $S$, in the previous chapter is of probabilistic nature. It is aimed therefore in this chapter to calculate the seismic cost in a probabilistic manner as well. The probabilistic nature of subsidence, $S$, which is termed limit state in this section is estimated by 1) seismic hazard analysis, 2) fragility analysis, and 3) estimation of limit state probability.

\section{Seismic Hazard Analysis}

A seismic hazard curve defines the probabilistic nature of an index that expresses the intensity of an expected earthquake. The peak ground acceleration is frequently employed as this index. Annaka and Yashio (2000) proposed a probabilistic model, which consists of a seismic source model and an attenuation model which was developed on the basis of records obtained by the JMA-87 strong motion accelerometer network of the Japan Meteorological Agency (JMA). Note that Tokyo Metropolitan Area is a region of high seismicity, where large inter-plate, intra-plate, and inland crustal type earthquakes occur frequently.

The present study requires a time history of seismic acceleration to be defined because the subsidence of an embankment is calculated by the Newmark (1965) analogy. Hence, many earthquake motions have to be employed with varying types of earthquake, epicentral distance, and magnitude $(M)$. Sensitivity analyses on the seismic hazard in the concerned region, however, suggests that the most influential earthquakes are the inter plate type of $M=8$ class and the one with $M=7$ class at a short epicentral distance. Accordingly, two seismic hazard curves are constructed.

Response spectra were developed for both earthquake types by the model of Annaka and Nozawa (1988), which is an attenuation model of response spectra constructed from the observation data set in Tokyo metropolitan area. Then time histories of two artificial earthquake motions are made so that they may be compatible with the given response spectra. Phase spectra of an observed earthquake motion with its epicentral distance and magnitude similar to the target earthquake was used to generate the artificial earthquake motions. The hazard curves

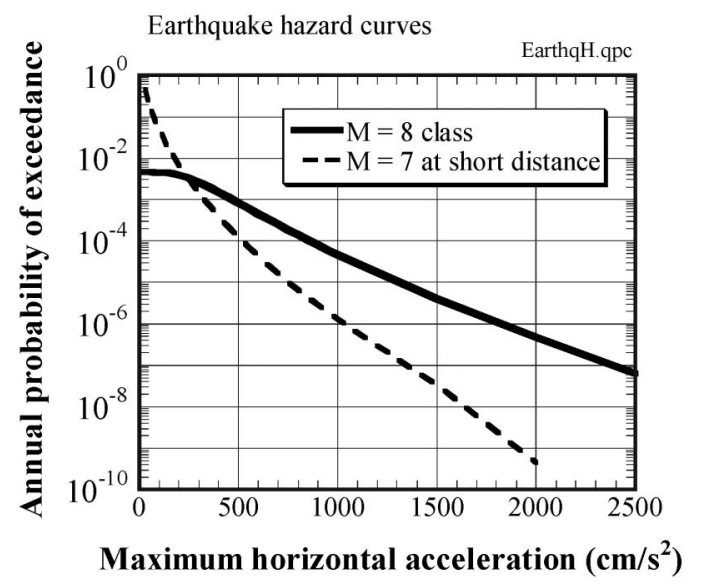

Fig. 12. Seismic hazard curves for two kinds of design earthquakes

and corresponding earthquake motions are shown in Figs. 12 and 8, respectively. Note that these two design motions are of different frequency components because of their different earthquake magnitudes. Moreover, the hazard curve, $F_{\mathrm{h}}(a)$, demonstrates the probability that the peak acceleration of $a$ is exceeded in reality within a unit time. By using the probabilistic density function, $f_{\mathrm{h}}(a)$ for $a$,

$$
F_{\mathrm{h}}(a)=\int_{a}^{\infty} f_{\mathrm{h}}(a) d a
$$

More precisely, this curve gives the probability of exceedance during the life period of $n=80$ years. It is hence given by using an annual probability of exceedance, $F_{\mathrm{h}}^{1}(a)$ :

$$
F_{\mathrm{h}}(a)=1-\left\{1-F_{\mathrm{h}}^{1}(a)\right\}^{n}
$$

Note that there are two hazard curves, $F_{\mathrm{h} 1}(a)$ and $F_{\mathrm{h} 2}(a)$, because two kinds of design earthquakes are employed. Moreover, the discount ratio is assumed to be zero, which means that the amount of loss is independent of the year of earthquake occurrence.

\section{Fragility Analysis}

The seismic fragility is also a key ingredient of seismic risk assessment, describing the conditional probability of failure as a function of seismic intensity. A fragility curve shows the probability of seismic consequence exceeding the limit state value for a given seismic intensity. In this study, the peak ground acceleration $(a)$ is employed as the seismic intensity index.

The present study focuses on the subsidence of an expressway embankment, $S$, induced by earthquakes, and limit states are defined in terms of $S$. The following discussion addresses the probability that $S$ exceeds an example limit state of $S=S_{\mathrm{r}}=0.5 \mathrm{~m}$. The fragility, $F_{\mathrm{f}}(a)$ is defined by

$$
F_{\mathrm{f}}(a)=\int_{0}^{R_{\mathrm{r}}} f_{\mathrm{f}}(r) d r
$$

in which $f_{\mathrm{f}}(r)$ stands for the probabilistic density of 


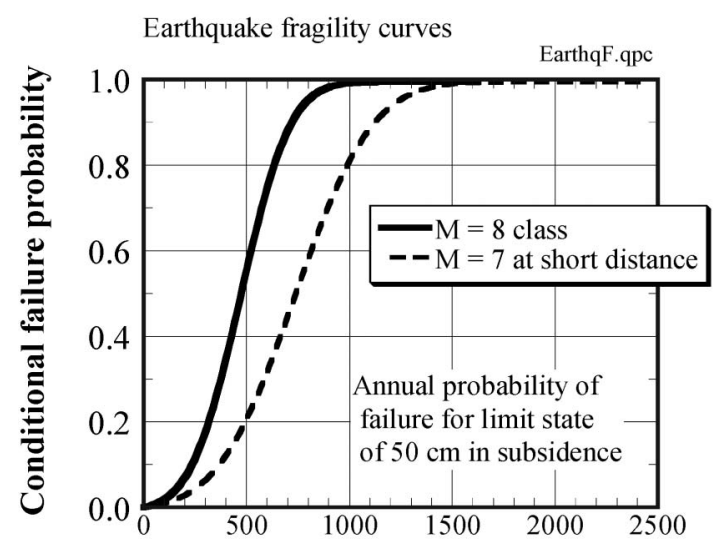

Maximum horizontal acceleration $\left(\mathrm{cm} / \mathrm{s}^{2}\right)$

Fig. 13. Examples of fragility curves for limit state of $50-\mathrm{cm}$ subsidence

resistance, $r$, against subsidence or deformation, and $R_{\mathrm{r}}$ is the resistance that generates the subsidence exactly equal to $S_{\mathrm{r}}$. Evidently this resistance varies with the acceleration, $a$. See Fig. 13 for an example.

While subsidence, $S$, is calculated by the Newmark rigid block analogy, the state of $S>S_{\mathrm{r}}$ is considered to be a damage. In principle, subsidence is affected by such uncertain factors as types of earthquakes $(j=1$ or 2$)$, the peak acceleration $(a)$, and parameters of $x$ that represent local conditions (soil and geometry). It is, however, believed that the uncertainty in ground motion is more significant than the effects of all other uncertainties (Celik and Ellingwood, 2007). This suggests that a variation of fragility is relatively insignificant.

It is important in the present study to take into account many kinds of uncertainty involved in material properties of soils, modeling, etc. Consequently, fragility curves are assumed to follow a lognormal distribution. Coefficient of variance $(\mathrm{COV})$ of the distribution is assumed to be 0.4 . Although the authors examined the consequence of $\mathrm{COV}=0.3$ and 0.5 , the obtained LCC was similar. The median value of the lognormal distribution is given by the peak acceleration $(a)$ at which the estimated subsidence, $S$, is equal to the prescribed $S_{\mathrm{r}}$.

Figure 13 presents two fragility curves for the limit state subsidence of $S_{\mathrm{r}}=50 \mathrm{~cm}$. They correspond to two different seismic motions. The significant difference between them comes from the fact that the earthquake motion of $M=8$ class has a longer duration time and greater low frequency components, generating greater seismic displacements.

\section{Estimation of Seismic Risk for Expressway Model}

The probability of failure is calculated by using the hazard and fragility curves discussed above for which two types of earthquakes are considered. The probability of subsidence exceeding $S$ ( $=0.5 \mathrm{~m}$ for example) is given by

$$
P(S)=\sum_{\mathrm{j}=1}^{2} \int_{0}^{\infty} f_{\mathrm{hj}}(a) \int_{0}^{R_{\mathrm{r}}} f_{\mathrm{fj}}(r) d r d a
$$

as a summation for two types of earthquakes. By changing the order of integration,

$$
\begin{aligned}
P(S) & =\sum_{\mathrm{j}=1}^{2} \int_{0}^{\infty} f_{\mathrm{fj}}(r) \int_{a}^{\infty} f_{\mathrm{hj}}(\eta) d \eta d r \\
& =\sum_{\mathrm{j}=1}^{2} \int_{0}^{\infty} F_{\mathrm{hj}}(a) \frac{\mathrm{d} F_{\mathrm{fj}}}{\mathrm{d} a} d a
\end{aligned}
$$

The seismic cost, $C$, is determined by integrating the product of the probabilities and their consequences. Since $P(S)$ is a probability of exceedance,

$$
\begin{aligned}
C & =\int_{S_{\text {minimum }}}^{\infty}\left(-\frac{\mathrm{d} P}{\mathrm{~d} S}\right) D_{\mathrm{e}}(S) d S \\
& =\left[-P D_{\mathrm{e}}\right]_{S_{\text {minimum }}^{\infty}}^{\infty}+\int_{S_{\text {minimum }}}^{\infty} P \frac{\mathrm{d} D_{\mathrm{e}}}{\mathrm{d} S} d S
\end{aligned}
$$

Since $P$ (probability of exceedance) is null at $S=\infty$ and $D_{\mathrm{e}}$ is null at the minimum subsidence, the first term in Eq. (12) vanishes. Accordingly,

$$
C=\int_{S_{\text {minimum }}}^{\infty} P \frac{\mathrm{d} D_{\mathrm{e}}}{\mathrm{d} S} d S
$$

The indirect cost is related to the interruption of the expressway that occurs when any of the three embankments in Fig. 7 collapses. On the other hand, the direct cost is related to the failure of each embankment. Therefore, the seismic risk $C_{\mathrm{e}}$ is determined by

$$
C_{\mathrm{e}}=C^{\text {in }} P\left(\bigcup_{\mathrm{i}=1}^{3} E_{\mathrm{i}}\right)+\sum_{\mathrm{i}=1}^{3}\left(C^{\mathrm{d}} P\left(E_{\mathrm{i}}\right)\right)
$$

where $C^{\text {in }}$ is the indirect cost, $E_{\mathrm{i}}$ designates a failure event in embankment $i$, and $C^{\mathrm{d}}$ is the direct cost of a single embankment.

\section{Detailed Calculation}

In an ordinary approach, several limit states are defined, and then a fragility curve is developed to describe the probabilities that a structure exceeds each defined limit state when subjected to a specific seismic intensity level. The present study, in contrast, takes a different way in which limit state is continuous. This implies that the subsidence of $S$ in the cost calculation is not a discrete variable but a continuous variable as illustrated in Fig. 10. By combining the equations so far presented, the seismic risk $C_{\mathrm{e}}$ is calculated by assuming continuity in limit state,

$$
\begin{aligned}
C_{\mathrm{e}}= & \sum_{\mathrm{j}=1}^{2} \iint \frac{d C^{\mathrm{in}}(s)}{d s} F_{\mathrm{hj}}(a) \frac{d F_{\mathrm{fj}}^{\mathrm{in}}(a \mid s)}{d a} d a d s \\
& +\sum_{\mathrm{j}=1}^{2} \sum_{\mathrm{i}=1}^{3} \iint \frac{d C_{\mathrm{i}}^{\mathrm{d}}(s)}{d s} F_{\mathrm{hj}}(a) \frac{d F_{\mathrm{fij}}^{\mathrm{d}}(a \mid s)}{d a} d a d s
\end{aligned}
$$

in which $F_{\mathrm{fj}}^{\mathrm{in}}(a \mid s)$ and $F_{\mathrm{fij}}^{\mathrm{in}}(a \mid s)$ designate indirect and direct fragility curves for a limit state defined by subsidence $S$. Moreover, $C^{\text {in }}(s)$ and $C^{\mathrm{d}}(s)$ are indirect and direct losses at subsidence of $S$, respectively. The indirect loss in the first term occurs if one of the three critical embankments is damaged, and, in contrast, the direct loss in 
the second term is calculated for each of the critical embankments separately $(i=1,2$, and 3$) . F_{\mathrm{hj}}(a)$ stands for a seismic hazard curve for a seismic event of type $j$ and $F_{\mathrm{fi}}^{\mathrm{d}}$ denotes a fragility curve for indirect loss, which is the fragility against failure of any of the three embankments, while $F_{\mathrm{fi}}^{\mathrm{d}}$ expresses the fragility of an individual embankment $i$. The first and second terms in Eq. (15) indicate indirect and direct risk, respectively. It is assumed that seismic forces at the three sites are perfectly correlated, and fragilities of the three embankments are independent. The fragility for indirect loss is expressed with the fragility of each embankment:

$$
F_{\mathrm{fj}}^{\mathrm{in}}(a \mid s)=1-\prod_{\mathrm{i}=1}^{3}\left(1-F_{\mathrm{fij}}^{\mathrm{d}}(a \mid s)\right)^{3}
$$

Hazard curves in Fig. 12 show annual probability of exceedance. In order to estimate failure probability during $n$ years, the annual hazard curve $F_{\mathrm{hj}}^{1}$ is transformed as follows:

$$
F_{\mathrm{hj}}(a)=1-\left(1-F_{\mathrm{hj}}^{1}(a)\right)^{n}
$$

In the risk estimation below, the working period or the life cycle is assumed to be 80 years.

\section{REMARKS ON CALCULATED LIFE CYCLE COST}

Seismic risks were calculated on all of the fifty design cases in Fig. 3. Figures 14 and 15 present the estimated risk for a design earthquake of magnitude $(M)=8$ and the other with smaller magnitude. It is noteworthy therein, that the risk of indirect loss is remarkably greater than that of direct loss. This indirect loss will later make the LCC consideration meaningful. It should be understood, therefore, that those structures with less economic importance are not appropriate for LCC-based design. In Figs. 14 and 15, moreover, at high improvement ratio, the risk

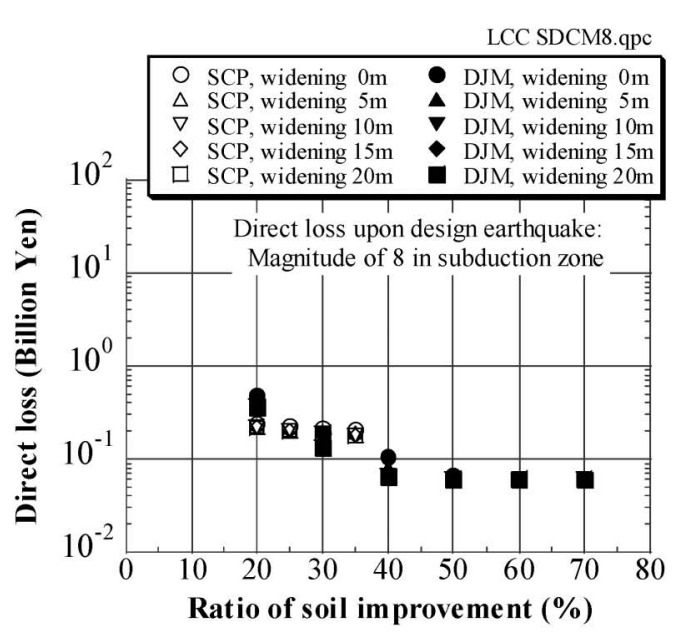

(1) Direct cost

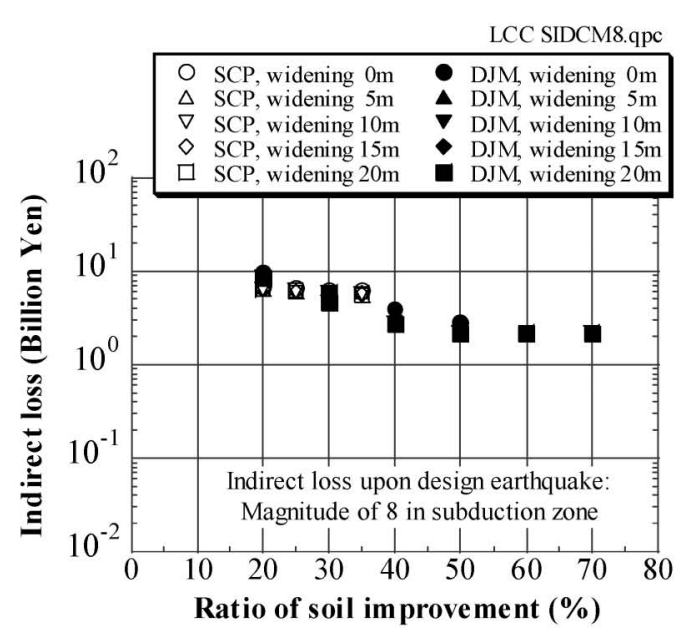

(2) Indirect cost

Fig. 14. Seismic risk due to M8-type earthquake

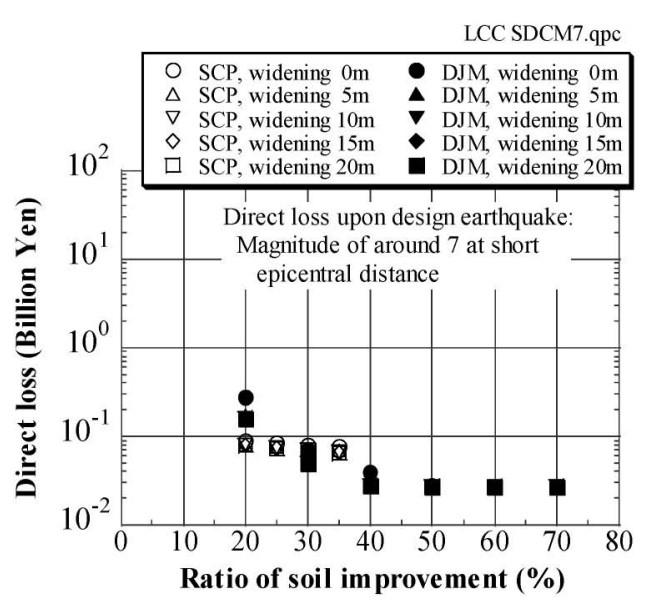

(1) Direct cost

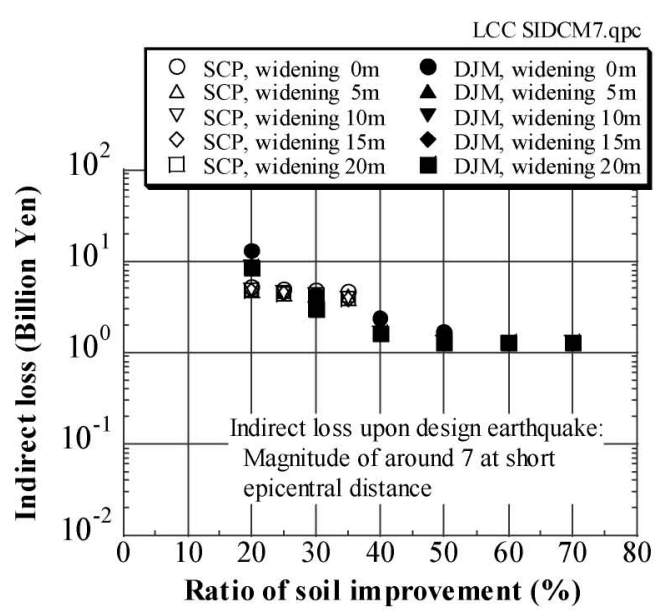

(2) Indirect cost

Fig. 15. Seismic risk due to earthquakes of $M=$ around 7 at short epicentral distance 


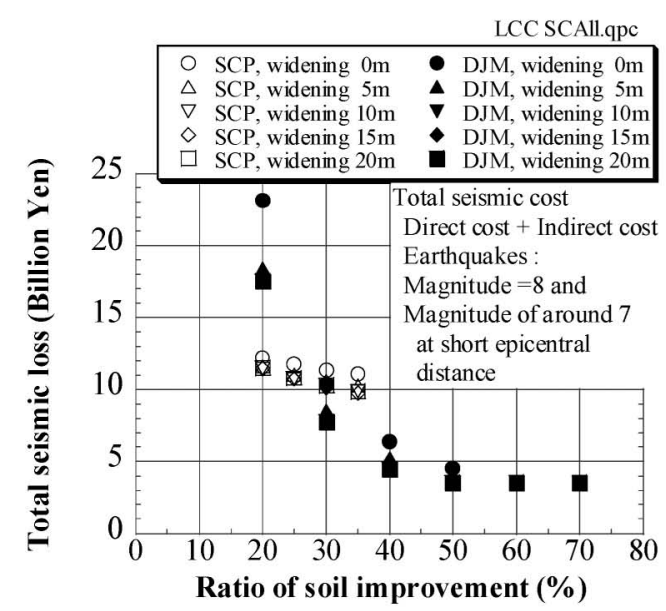

(1) Total seismic risk

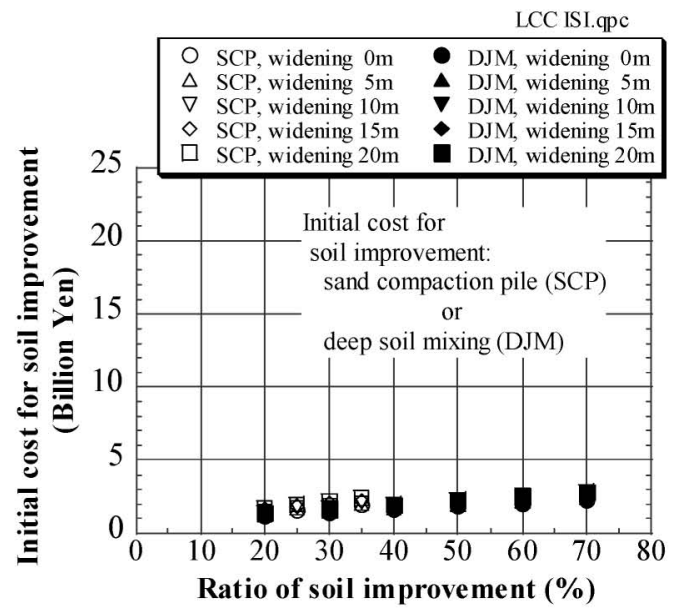

(2) Initial cost

Fig. 16. Total seismic risk and initial cost

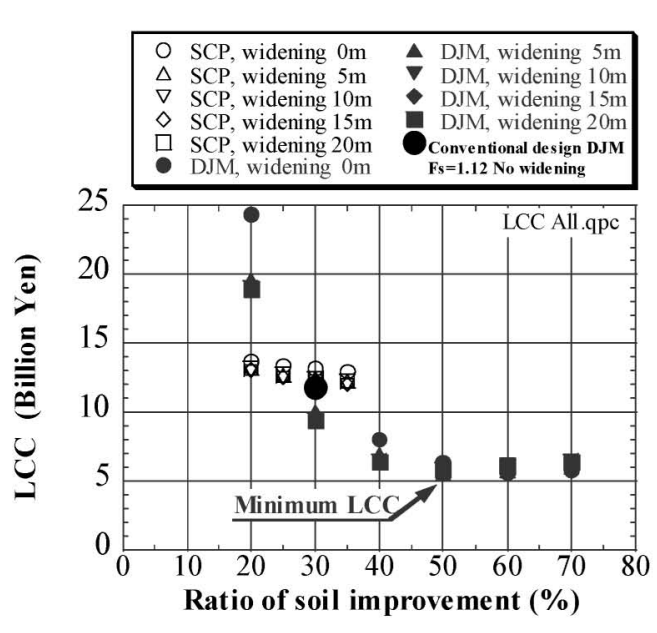

(1) LCC vs. improvement ratio

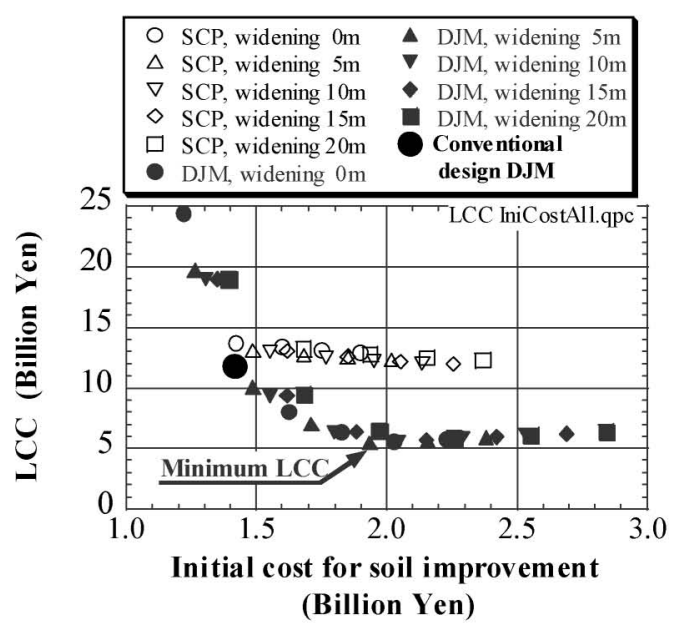

(2) LCC vs. initial cost

Fig. 17. Comparison of LCC for all design alternatives

that associates with the $M=8$ quake is greater than that of lower magnitude because large seismic intensity of the former quake is able to induce damage. Figure 16 reveals the total seismic risk, concerning two types of design earthquake, and the initial cost. The high ratio of subsoil improvement is able to reduce the seismic risk significantly, while it generally increases the initial cost needed for improvement. The seismic risk is nearly constant in the range of high improvement ratio, because, in this situation, the slip plane as employed by the Newmark sliding analysis occurs within the embankment and is not affected by further improvement in the subsoil. For this reason, the extent of SCP in excess of $40 \%$ does not affect the seismic risk.

LCC is defined as the sum of initial cost and seismic risk. The estimated LCC values for all the cases are indicated in Fig. 17. In the case of DJM, the seismic risk decreases rapidly with respect to the improvement ratio, and the LCC curve attains virtually the minimum value. This implies that the soil improvement effort of 1.9 billion Yen with the ratio of $50 \%$ at three embankments is sufficient and optimum, and that further increase in the initial cost is unnecessary. The design plan determined by the conventional method is also shown in Fig. 17. The initial cost of minimum LCC case is 1.9 billion Yen, while that of the conventional design is 1.4 billion Yen. This suggests that more initial investment is needed to construct the expressway embankment in this area from the viewpoint of minimum LCC.

To compare the conventional and LCC-based principles in more detail, Fig. 18 illustrates the variation of LCC with the conventional seismic factor of safety. It is interesting to note that LCC monotonously decreases as the factor of safety increases. Thus, types and extents of subsoil improvement do not affect the general trend of LCC. Similarly, Fig. 19 exhibits the relationship between 


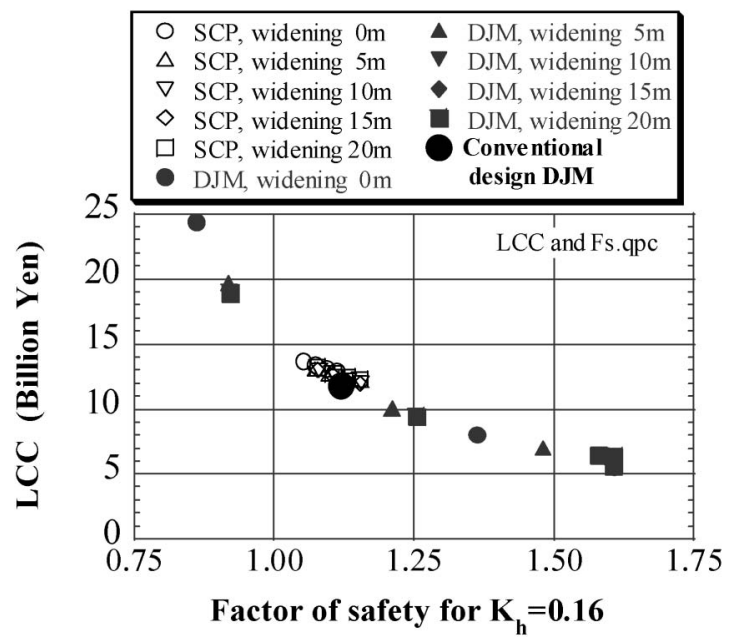

Fig. 18. Variation of LCC with conventional seismic factor of safety

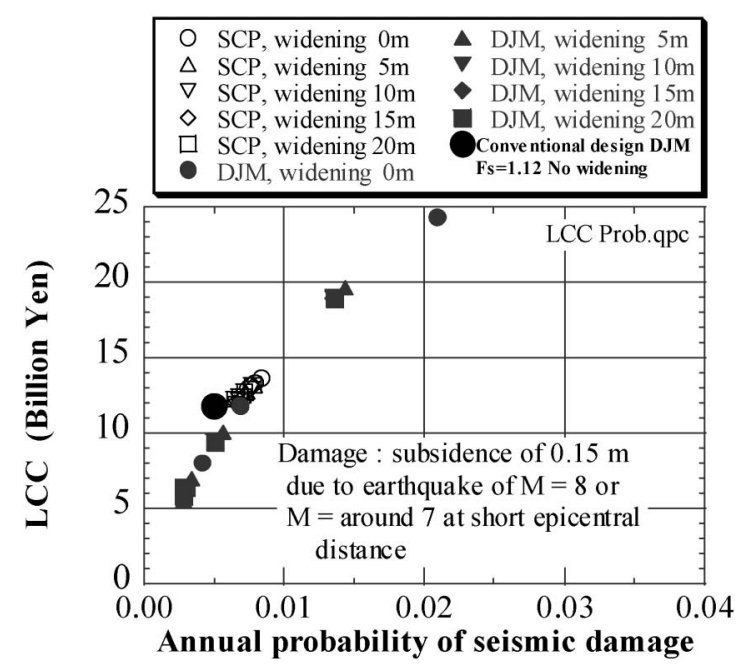

Fig. 19. Relationship between LCC and damage probability

the annual probability of damage and LCC. The damage is defined by the subsidence of $0.15 \mathrm{~m}$ due to an earthquake. Evidently, details of soil improvement do not affect the illustrated relationship.

Finally, the effects of the traffic interruption in the expressway on the regional and national economy have to be addressed. The authors discussed this issue significantly, considering the following points:

(1) the industrial activities and production may be reduced by the traffic problem,

(2) clients and consumers may find a new place of production,

(3) consequently, the new manufacturer may get more profits from the increased business.

Thus, both gain and loss occur in parallel. The conclusion of the present study is that the negative effect to the economy is not explicitly calculated because this effect is somehow taken into account in the detour loss $\left(D_{3}\right)$ due to elongated travel time.

\section{CONCLUSION}

An attempt was made to demonstrate and compare seismic designs of an embankment on the basis of a conventional pseudo-static principle and a new principle of life cycle cost. The following conclusions were drawn from this study:

1) The seismically-induced subsidence was employed as an index of limit state that varies continuously with the extent of earthquake effects.

2) Procedures to calculate the risk and consequence with respect to the subsidence were developed and demonstrated.

3) Seismic hazard and fragility curves were estimated separately for an $M=8$-class inter-plate earthquake and the one of smaller magnitude at a shorter epicentral distance. After seismic damage was probabilistically estimated separately for each of the two design earthquakes, the total probability was obtained by summing them up.

4) Consequence analysis is a very important part in risk estimation. The indirect loss was assessed using a cost-benefit analysis procedure for road investment. It is shown that the indirect loss, especially the elongated travel time due to detour, exerts a strong influence on the decision making in a LCCbased design.

5) Consideration on LCC may give a design conclusion that is different from that from the conventional design. This is particularly the case when a concerned structure plays an important role in the regional and the national economy. It, however, does not directly mean that the conventional design is not rational. Design procedures (specification) should be drafted considering many aspects. LCC considering seismic risk can be used as useful information for better code writing.

\section{ACKNOWLEDGMENT}

This research was supported by the NEDO Grant supplied by the New Energy and Industrial Technology Development Organization. Practical information on various costs concerning geotechnical structures were supplied through interview at the Ministry of Land, Infrastructure, Transport and Tourism, Tokyo Metropolitan Government, Public Works Research Institute, East Nippon Expressway Company, and National Institute for Rural Engineering among others. These supports and assistances are deeply appreciated by the authors.

\section{REFERENCES}

1) Annaka, T. and Nozawa, Y. (1988): A probabilistic model for seismic hazard estimation in the Kanto district, Proc. 9th World Conf. Earthquake Engineering, II, 107-112.

2) Annaka, T. and Yashiro, H. (2000): Uncertainties in a probabilistic model for seismic hazard analysis in Japan, Proc. 2nd Int. Conf. Computer Simulation in Risk Analysis and Hazard Mitigation, 369-378. 
3) Australian/New Zealand (2004): Risk Assessment, AS/NZS 4360, Third Edition.

4) Celik, O. C. and Ellingwood, B. R. (2007): Uncertainty analysis in fragility assessment of reinforced concrete frames designed for regions of low-to-moderate seismicity, Applications of Statistics and Probability in Civil Engineering, Proc. ICASPIO.

5) Furuta, H. and Frangopol, D. M. (2005): Life-cycle cost analysis of reinforced concrete bridge piers considering seismic performance, Proc. 8th Int. Conf. Structural Safety and Reliability, 1377-1384.

6) ISO/IEC, Guide 73 (2002): Risk management-VocabularyGuidance for use in standards.

7) ISO TC 98/SC3/WG10, ISO23469 (2004): Basis for design of structures-Seismic actions for designing geotechnical works.

8) Japan Road Association (1999): Road earth work, slope protection, slope stabilization guideline (in Japanese).

9) Jones-Lee, M. W., Hammerton, M. and Philipps, P. R. (1985): The value of safety: Results of a National Sample Survey, Economic Journal, 95(377), 49-72.

10) Newmark, N. M. (1965): Effects of earthquakes on dams and embankments, Geotechnique, 5(2), 137-160.

11) Public Works Research Institute (2004): Manual for risk analysis and management of road slope failures (draft), Report No. 3926 (in Japanese)

12) Rackwitz, R. (2002): Optimization and risk acceptability based on the life quality index, Structural Safety, 24, 297-331.

13) Rackwitz, R. (2004): Life quality index revisited, Structural Safety, 26, 443-451.

14) Railway Technical Research Institute (2003): Design Standards for Railway Structures and Commentary (Seismic Design) (in Japanese).

15) Research Committee on Assessment of Investment on Road (1998): Guideline, p. 68 (in Japanese).

16) Stewart, M. G. and Melchers, R. E. (1997): Probabilistic risk assessment of engineering systems, Chapman \& Hall, Melcher and Stewart, Risk Management.

17) Takahashi, Y., Kiureghian, A. D. and Ang, H.-S. A. (2004): Lifecycle cost analysis based on a renewal model of earthquake occurrences, Earthquake Engineering and Structural Dynamics, 33, 859-880.

18) Yoshida, I. (2005): Fragility analysis and life cycle cost assessment considering risk, Proc. 8th Int. Conf. Structural Safety and Reliability, 1459-1464. 